\title{
Mechanical versus bioprosthetic mitral valve replacement in patients younger than 65 years
}

\author{
Thierry-Pierre Carrel, MD, and Lars Englberger, MD
}

See related article by Kaneko et al in the January 2014 issue (J Thorac Cardiovasc Surg. 2014;147:117-26).

The group of Cohn and colleagues from Boston ${ }^{1}$ analyzed the outcome of patients who received either mechanical or biologic mitral valve replacement (MVR) by means of a propensity score analysis. The topic is timely for publication, because there has actually been a shift to the use of bioprosthetic valves in younger patients as a result of potentially feasible later "valve-in-valve" procedures. Unfortunately, although technically feasible, a valve-invalve procedure remains questionable, especially with regard to optimal hemodynamics. Although the decision currently is not based on available scientific evidence, general practitioners and cardiologists are increasingly recommending biologic prostheses to patients younger than 60 years.

The same group recently summarized some of the myths surrounding heart valve prostheses in an article on controversies in cardiovascular medicine. ${ }^{2}$ The main topics discussed were the survival of such patients, the need or not for lifelong anticoagulation, the risk of reoperative surgery, and the quality of hemodynamics.

If repair of a mitral valve is not possible, the question persists whether a biologic or a mechanical prosthesis should be preferred for MVR. Recent changes in guideline recommendations (eg, age $<65$ years no longer being a clear cutoff for implantation of a mechanical prosthesis) and the promise of percutaneous valve-in-valve rescue after bioprosthetic mitral valve placement have complicated decision making in MVR.

The most important reasons to implant a bioprosthesis in adults younger than 65 years is to decrease the risk of anticoagulant-related hemorrhagic events and to spare patients lifestyle-related restrictions related to warfarin

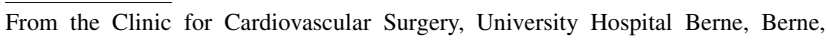
Switzerland.

Disclosures: Authors have nothing to disclose with regard to commercial support.

Received for publication Oct 7, 2013; accepted for publication Oct 22, 2013; available ahead of print Nov 25, 2013.

Address for reprints: Thierry-Pierre Carrel, MD, University Hospital, Clinic for Cardiovascular Surgery, Freiburgstrasse, CH-3010 Berne, Switzerland (E-mail: thierry.carrel@insel.ch).

J Thorac Cardiovasc Surg 2014;147:853-4

$0022-5223 / \$ 36.00$

Copyright (C) 2014 by The American Association for Thoracic Surgery http://dx.doi.org/10.1016/j.jtcvs.2013.10.020
}

use. Two presumptions, however, are inherent in this argument: (1) survival of patients after MVR is similar between mechanical valves and bioprostheses, and (2) current bioprostheses have longer durability than previous valve designs, especially in the mitral position. ${ }^{4}$

The article of Cohn's group focuses on the long-term outcome after mechanical versus bioprosthetic MVR in patients younger than 65 years. Although derived from a retrospective analysis, this report contains important information, because no randomized trials comparing latest generation bioprosthetic versus mechanical valves in MVR have yet been performed. The main finding is very clear: MVR with bioprosthetic valves in patients younger than 65 years was associated with higher rates of reoperation and decreased survival than was MVR with mechanical valves. This was true for the total consecutive cohort of patients as well as for the score-matching subgroup analysis. Interestingly, these results confirm other reports of aortic valve replacement in patient cohorts of younger age, in which survival benefits could be demonstrated after use of a mechanical prosthesis. ${ }^{5,6}$

One minor criticism of the article is that the propensity analysis included patients with a mean age of 53 years. This is usually not the category of patients in whom there is discussion concerning the choice of a biologic mitral valve prosthesis. Patients with a mean age of around 60 to 65 years would have had a better impact for the daily discussion.

Which factors may explain the finding of better patient survival with mechanical valve use for MVR? In fact, several possible explanations other than the mere difference in valve selection are obvious.

The observational retrospective character of this study does not exclude the possibility that patient characteristics (not included in the matching process) could have importantly confounded the results. Even the matching process does not compensate for the bias in patient selection with regard to similar comorbidities (eg, peripheral artery disease or concomitant pulmonary disease are not reported) and a similar extent of aortic valve disease. Bioprosthetic valves could have been preferably implanted in patients who generally appeared to be more ill and therefore to have a less favorable presumed life expectancy. We believe that bioprosthetic valve use for MVR in younger patients was not performed solely for quality-of-life considerations (because of the possible benefit of avoiding warfarin) but also in response to favorable (or less favorable) clinical characteristics obvious on clinical evaluation but not 
captured in clinical databases used for further analysis of the patient group. This consideration may be supported by the high rate of warfarin therapy for new-onset atrial fibrillation in the bioprosthetic valve group, which could be a sign of advanced cardiac disease.

In addition, differences in survival observed after mechanical versus biologic prosthetic valve replacement may have been influenced by the intrinsic performance of the prosthesis and the benefits of long-term anticoagulation. After the implantation of a biologic valve, there is not only the risk of reoperation for degeneration of this valve but also the adverse cumulative hemodynamic effect of living with a degenerating bioprosthesis in place. This may add a plausible explanation for the improved survival of patients with mechanical valves. ${ }^{4}$ Primary tissue failure of a bioprosthesis may occur earlier in younger patients and progress more rapidly, and this means that such patients would be exposed during months or years to a significant malfunction of the bioprosthesis by regurgitation, stenosis, or both before complete prosthetic failure is identified and re-replacement is recommended. In this respect, rates and risks of reoperation underestimate the impact of valve failure on mortality.

Even if the conclusions of this study should clearly not be extrapolated to the older ( $\geq 65$ years) patient population, in which survival after MVR is even more related to patient comorbidity and not to valve type alone, recommendations for the younger age group of patients ( $<65$ years) should not be biased by fashionable slogans (bioprostheses for all patients) or still unproven concepts yet (valve-in-valve therapy). The evidence to recommend a bioprosthetic valve for MVR for most younger ( $<65$ years) patients without relevant comorbidity is still not here. Lifestyle considerations may be important too, but they should never be placed above the scientific evidence.

\section{References}

1. Kaneko T, Aranki S, Javed Q, McGurk S, Shekar P, Davidson M, et al. Mechanical versus bioprosthetic mitral valve replacement in patients $<65$ years old. J Thorac Cardiovasc Surg. September 27, 2013 [Epub ahead of print]

2. Kaneko T, Cohn LH, Aranki SF. Tissue valve is the preferred option for patients aged 60 and older. Circulation. 2013;128:1365-71.

3. Joint Task Force on the Management of Valvular Heart Disease of the European Society of Cardiology (ESC); European Association for Cardio-Thoracic Surgery (EACTS); Vahanian A, Alfieri O, Andreotti F, Antunes MJ, Barón-Esquivias G, Baumgartner H, et al. Guidelines on the management of valvular heart disease (version 2012). Eur Heart J. 2012;33:2451-96.

4. Suri RM, Schaff HV. Selection of aortic valve prostheses: contemporary reappraisal of mechanical versus biologic valve substitutes. Circulation. 2013;128: 1372-80.

5. Weber A, Noureddine H, Englberger L, Dick F, Gahl B, Aymard T, et al. Ten-year comparison of pericardial tissue valves versus mechanical prostheses for aortic valve replacement in patients younger than 60 years of age. J Thorac Cardiovasc Surg. 2012;144:1075-83.

6. Brown ML, Schaff HV, Lahr BD, Mullany CJ, Sundt TM, Dearani JA, et al. Aortic valve replacement in patients aged 50 to 70 years: improved outcome with mechanical versus biologic prostheses. J Thorac Cardiovasc Surg. 2008;135: 878-84; discussion 884 . 